\title{
Conclusions: Reframing the Possibilities for Natural and Social Science Dialogue on the Economic History of Natural Resources
}

\author{
$\underline{\text { Rosemary E. Ommer }}^{1}$ and Barbara Paterson ${ }^{2,3}$
}

Key Words: fisheries; social-ecological systems

Ecology and Society has few historical essays in its issues, which is a very important lacuna because historical depth is an invaluable aid to understanding problems in the present day, what went wrong, and thus what may be the way to move on productively. Moreover, Ecology and Society papers that do deal with historical matters are focused mostly on conservation issues or those of First Nations. There is, however, another global phenomenon that needs to be covered in historical socialecological thinking, and that is the problems faced over the long term by local fisheries around the world. Such local, often but not always small-scale, fisheries have been the mainstay of rural coastal populations globally for countless generations. Many local fish stocks are increasingly threatened by overfishing, stock collapses, and the migration of people and of fish as the planet warms. In the past, local coastal communities traditionally showed the flexibility needed to survive, partly through occupational pluralism and partly through the development and use of traditional ecological knowledge. Although a great deal is known about the traditional 19th- and 20th-century economic history of some local fisheries, not enough is known about how this crucial occupational sector has responded to the increasing social-ecological pressures that have resulted from the operations, post 1950, of deep-sea locationally footloose industrial fleets.

Natural resources, particularly renewables, are, and always have been, subject to impacts from many directions, ranging from what natural scientists refer to as "anthropogenic impacts" to alterations in the environment caused by climate change. The natural world is complex, in and of itself, and what happens in and to it can radically alter the context in which human economies function, and thus also the economies themselves. However, economic historians, myself (Ommer) included, have all too often sought explanations for changing resource exploitation over time in terms of other factors, i.e., altered tastes, shifting technologies, and the pulses of short- and long-term business cycles, to name just a few. We did not consider, that is, it certainly did not enter my consciousness, that renewable resources would be in danger of becoming nonrenewable under conditions of extreme exploitation that destroyed the population base of the stock.

In 1987, I was asked if the poor fisheries of eastern Canada in the 1840 s could have a been a result of overfishing. I answered that there was no evidence to support that analysis (Ommer 1990). It is true that there was no such evidence then, but the problem was that no one had ever thought to see if it existed. For centuries, many eminent and ordinary people thought the resources of the sea were without limit (FAO 2009). By the 1980s, we knew that was not the case but still thought problems with overfishing were for the most part a recent phenomenon that was relatively easily fixed. That was another misconception: there is evidence of overfishing in the past, even as early as the 1840s (see Cadigan 2003). However, very few people were willing or able to grasp the idea that the boundless oceans might actually be bounded. Those who were beginning in the 1980 s to worry were scientists, not historians, and historians did not talk to scientists in those days: We thought there was nothing to talk about. In this new century, however, humanity at large is being forced to pay attention to the environment, and our interactions with it, as climate change starts to alter resource patterns and as human exploitation and technological innovation push some natural resources toward ecosystem tipping points.

The old economic history ideas about staples as the basis for regional and national development bear witness to the mind-set that saw, and still sees, natural resource extraction as one fruitful path to development, or, if mishandled, as an explanation of economic development "failure." Natural resources, exploited for markets abroad, in the first instance, were, and sometimes still are, seen as the engine for growth, leading over time to domestic economic development so long as the formation of forward, backward, and final demand linkages occurred. When that happened, the old staple base would be sloughed off, and manufacturing would secure continued economic growth (see, among others, Baldwin 1956, North 1961, Watkins 1963, Gilmour 1972, Ommer 1990). In some countries, fisheries and their linkages were seen as engines for growth; however, in others, the linkage development stages were ignored, and fish came to be seen as an inadequate or "failed" staple. The contrasting cases of Newfoundland and Iceland are a case in point, to which I drew attention in the 1980s (Ommer 1988).

In the years of the 19th century after the Industrial Revolution, and then in postcolonial days, as manufacturing became the engine for growth in underdeveloped regions and as the developed world moved increasingly to the service sector, including finance and development, natural resource exploitation, which is always international to some degree, went global, and thus it became increasingly possible to avoid mostly national, or at best regional, regulatory controls that frequently lacked any teeth. The end result has been our inability to effectively control the pillaging of the oceans and many of the other natural resources of this planet. From the collapse of the groundfish stocks of the northern northwest Atlantic, to, and beyond, the destruction of the Amazon forests, we have been treading a dangerous path,

\footnotetext{
${ }^{1}$ Departments of History and Geography, University of Victoria, ${ }^{2}$ Marine Research Institute (Ma-Re), Zoology Department, University of Cape
} Town, ${ }^{3}$ Community-University Research for Recovery Alliance (CURRA), Department of Sociology, Memorial University of Newfoundland 
arrogantly certain that we will always find the technology to increase wealth and repair any unfortunate damage along the way. In the 200 years since the Industrial Revolution, we have wreaked more havoc on the natural environment that sustains us than did the preindustrial world or than those still extant Indigenous societies, which we think of as needing to be brought into the developed world, have done. However, it is cultures such as those of the First Nations of the British Columbian coast that know what sustainability really means, having recognized their interdependence with nature and hence having learned to be respectful of it, as their mythological tales emphasize and as they can demonstrate through having, at contact with white colonists, 25,000 years of life along a coast that had remained, at that time, resource rich. There are many similar economic histories.

Most fisheries scientists, alerted by the collapse of many of the fish stocks whose former vastness made them seem inexhaustible, recognized by the 1970s that the traditional approach to managing the harvesting of our oceans had failed. This recognition resulted in the 1982 United Nations Convention of the Law of the Sea by which nations agreed to manage marine ecosystem resources based on the interdependence of ecosystem components. Since then, there have been numerous international initiates promoting the move to an ecosystem approach to fisheries (EAF). The move to an EAF has expanded this focus to also consider issues such as food web interactions, habitat considerations, and the effects of bycatch, as well as moving to participatory and spatial management approaches (Ommer et al. 2012). This broader focus means that where traditionally fisheries scientists' main concern was to apply population assessment models to determine, albeit unsuccessfully, how many fish could be caught and to find ways to limit access to the fishery resource to a manageable few, fisheries management problems have become a good deal more complex (Jentoft and Chuenpagdee 2009, Khan and Neis 2010). Complexity, however, can quickly become overwhelming and is an ongoing source of frustration for resource managers, who, while grappling with conflicting management objectives, need to operationalize fisheries management decisions (Paterson and Petersen 2010). Several tools have been put forward to provide a framework for fisheries management, starting with the 1995 Food and Agriculture Organization of the United Nations (FAO) Code of Conduct for Responsible Fisheries and resulting in the FAO Technical Guidelines for Responsible Fisheries series (FAO 2003) and the integration of human dimensions into an EAF (FAO 2009). What these tools have in common is that they are underpinned by a fisheries management framework that is based on three overarching goals: ecological well-being, human wellbeing, and good governance (FAO 2003). This management framework for EAF relies heavily on the development of specific measurable objectives and indicators for each of these top-level goals. It is assumed that objectives for ecological well-being are derived from an understanding of ecosystem functioning and the definition of optimum states, whereas objectives for human wellbeing are often considered to be value judgments, which depend on stakeholder preferences. We see several problems with this approach, discussed subsequently.

Positing ecological well-being, human well-being, and the ability to achieve EAF, i.e., through good governance, as separate categories does not reflect any possible linkages, let alone interdependencies, between these categories. However, if management works with neatly separated objectives, how will decision makers ever get out of their disciplinary silos when the very framework within which we are thinking separates the social from the ecological world? Because we know very well that ecological conditions are not only created through human activity, e.g., overfishing, but also affect human well-being, e.g., through fishery closures, indicating that they are interdependent, it seems obvious that fisheries management should pay attention to such linkages within social-ecological systems (Ommer et al. 2012). How else can management ever be prepared to address the unexpected local consequences? Jarre et al. (2013) document this clearly by tracing social and ecological linkages in the case of the South African small pelagic fishery. Their account shows how the vertically and horizontally integrated industry that characterizes the fishery today developed through an iterative process of both social and ecological restructuring. The analysis by Jarre et al. shows that these developments have not only marginalized inshore fishers but have also increased pressure on the resource, and this in spite of the conservation measures that were put in place to protect the long-term sustainability of the fishery and the industry that was built on it. Similarly, Neis et al. (2013) highlight the unintended effects of policy interventions after fishery closures in Newfoundland, Canada, and Norway. Their comparative study shows how policies aimed at downscaling the fishery have affected coastal communities, and in particular women and youths. As a result, the small-scale fisheries in both areas are disappearing, which means that wealth from the resources is no longer captured by local communities and households. Instead, control over resources and employment is increasingly shifting toward corporations. Interestingly, although the effects of the fishery closures on the cod (Gadus morhua) populations in the two areas differed, the effects of the postclosure policies on those fishing communities were very similar. Neis et al. (2013) conclude that the effects of policy interventions can be as important in shaping small-scale fisheries as resource status and ecology. Although the South African policy was aimed at industrial fishing, in the case of Newfoundland the example shows how the corporate shift is supported by policies that lack understanding of the social and socioeconomic fabric of which coastal communities are made.

The South African, Newfoundland, and Norwegian cases all highlight the need for fisheries management to pay attention to linkages, both between and within the various contexts that make up the wider social-ecological fishery system (Ommer et al. 2012). However, as far as the linkages are concerned, the management triptych of ecological well-being, human well-being, and good governance appears to be frozen in time. Although data time series allow the tracking of individual indicators over time, e.g., the number of people involved in a fishery or annual catch data per species, just tracking these indicators does not capture the relationship between these factors and the iterative restructuring that takes place between the social and the biophysical environments. A historical view of the linkages is important because it helps us understand how the wickedly complex situations of today have been created through successive interactive restructuring of the social and ecological conditions amongst which fishing and its management are taking place today. Prateep Nayak (2013), in his case study of Chilika Lagoon in India, stresses that history is shaped by a complex trajectory of 
interacting events that should not be divided into separate disciplinary perspectives. By the same token, a collection of individual data time series cannot adequately reflect the complex interactive social-ecological restructuring that has caused the wicked problems of today's fisheries in the first place.

This leads us to the third weakness of the management triptych. Management objectives are, or should be, a reflection of what we value in a fishery, such as a healthy ecosystem that supports healthy fish stocks, vibrant fishing communities, and a healthy fishing economy. The decline of many fish populations and the subsequent collapse of fisheries remained unnoticed by conventional economic measures that were focusing on catches, exports, and gross domestic product (GDP).

The problem with indicators is that they tend to essentialize some aspects while keeping others invisible. In addition, there is a danger of introducing scale issues and measuring aspects simply because data for those are available, albeit not at the right scale.

This is particularly true in the case of small-scale fisheries in developing countries, where governments often lack the resources to closely monitor the fisheries and often choose to focus instead on sectors whose contribution to the GDP is relatively more important. From the perspective of the national economy, this might seem sensible; however, from the perspective of impacts on the resource and on coastal communities, it clearly is not. Blythe et al. (2013) make this case for Mozambique, where disregarding the small-scale fishery has led to the underestimation of total fish catches. Their study adds to the growing body of literature that shows that more than one form of knowledge is required to keep track of the complex and interlinked realities of local fisheries. Although landings data provide valuable information about the productivity and status of a fishery, they do not provide any insights into how the interaction of these drivers of change influences realities at the local scale, i.e., the consequences on both people and fish. Similarly, Paterson et al. (2013) demonstrate how a management focus on maximizing jobs in the Namibian hake (Merlucius capensis and M. paradoxus) fishery has fallen short on maintaining the well-being of fish plant workers while placing additional pressure on an already depressed resource.

Thus, there is no doubt that the conventional measuring sticks are insufficient and that fisheries managers need a much broader set of objectives. However, deciding which indicators should be included in a management model is a value decision about what is important and what is not. Who gets to make this decision? It is widely assumed that fishery stakeholders should determine objectives for human well-being. However, such stakes or spaces of participation (Gaventa 2006) are shaped by power dynamics, which in turn have been shaped by the history of local fisheries. Marieke Norton (2013) illustrates the traditional and cultural importance of snoek (Thyrsites atun) in the Western Cape by tracing the various roles this fish has played over the centuries since the colonialization of this region at the southern tip of Africa. Although attempts to transform snoek into a staple for export failed, the fish has remained an important food source and captures some of the charismatic flair of the Cape Province. Moeniba Isaacs (2013), focusing on the same species, gives a detailed account of the important contribution that a small-scale fishery is making to food security and livelihoods in a particular community in the Western Cape, South Africa. Her case study is situated within the new democratic South Africa's struggle to make up for the past inequalities of the apartheid state. However, a policy framework that used individually transferable quotas to broaden access to the fishery resources has actually resulted in the corporate concentration of fishing and processing infrastructure, leaving many traditional small-scale fishers without access to the resources that are the basis of their livelihoods. A similar situation is found in Namibia, where the relative absence of a small-scale fishing sector has for a while disguised the fact that Namibian workers in the fishery have been marginalized. Mismatches in the economic fisheries policy, which, as Paterson et al. (2013) demonstrate, have not only prevented the trickling down of economic benefits to the poor, but are also obstructing the rebuilding of the Namibian hake fishery, an important cornerstone of the Namibian fisheries sector.

The evidence is conclusive that local fisheries are in retreat, as are many of the world's commercial fish stocks. The consequences of this for local communities in marginal areas of the Northern Hemisphere, or developing areas in the Southern Hemisphere, include a legacy of increasing underdevelopment, increasing food insecurity, and serious, although in most cases not yet irreparable, coastal social-ecological (marine) damage. The case studies presented in this issue show this clearly. They also have two other lessons for us. The first is that we cannot manage local fisheries according to a global blueprint. Of course, there are many commonalities between fisheries in different countries, and globalization has certainly increased these commonalities; however, there are still also the individual idiosyncrasies, the particularities of local situations. The second is that history matters: Where fisheries have come from shapes their options for the future to some significant degree. Thus, we need to learn much more about the interdependence of human society, including its economies, with the natural world. We also need to understand why present-day marine ecologies are in the shape they are in and what needs to be done to restore them. Thereafter, we need to learn how to prosecute them in genuinely sustainable ways, bearing in mind the interdependencies that their pasts so clearly reveal.

This collection of papers shows how to build that understanding of the natural resources on which we depend and which depend on our respectful behavior if they and we are to survive in the marine social-ecological symbiosis that has been too neglected until now. That understanding comes from knowledge of the component parts of the marine social-ecological system: modern resource science and the deep knowledge that local peoples have of the resources they harvest on a daily basis; understandings of how different societies work, now and in the past; and understanding, therefore, the inheritance from which socialecological systems have grown, either in a stunted manner or one that is flourishing. For that to work, social scientists and humanists need to understand marine natural ecology, and scientists need to understand more about society, not just its economics, but also its past and its present-day requirements. The resilience of social-ecological systems is poorly served by current resource-management frameworks. We do not manage resources; we attempt to manage the behavior of people. To do that well, we need to understand the motivations people have had for how they exploited resources in the past, as well as their motivations in the present, and what their social relationships have been and are 
today. Only then will we be able to come to grips with the imperatives of their cultural, social, and economic needs and expectations of the fisheries on which they depend.

Responses to this article can be read online at: http://www.ecologyandsociety.org/issues/responses. $\mathrm{php} / 5972$

\section{Acknowledgments:}

R. E. Ommer's travel to South Africa was funded from the Research Chair in Marine Ecology and Fisheries, the Benguela Current Commission, and the NRF SeaChange program's project on Fisher's Knowledge (PIs Lesley Green, Astrid Jarre, and Lance van Sittert). Barbara Paterson contributed to this article as part of ECOFISH, which is a project of the Benguela Current Commission, the Technical University of Denmark, and the University of Cape Town. Additional support was received from the South African Research Chair in Marine Ecology and Fisheries, the international science and technology agreement between South Africa and Namibia, and the African research project on knowledge production under the University of Cape Town's Programme for the Enhancement of Research Capacity (PERC).

\section{LITERATURE CITED}

Baldwin, R. E. 1956. Patterns of development in newly settled regions. Manchester School 24:161-179.

Blythe, J. L., G. Murray, and M. S. Flaherty. 2013. Historical perspectives and recent trends in the coastal Mozambican fishery. Ecology and Society 18(4): 65. http://dx.doi.org/10.5751/ ES-05759-180465

Cadigan, S. 2003. The moral economy of retrenchment and regeneration in the history of rural Newfoundland. Pages 14-42 in $\mathrm{R}$. Byron, editor. Retrenchment and regeneration in rural Newfoundland. University of Toronto Press, Toronto, Ontario, Canada.

Food and Agriculture Organization of the United Nations (FAO). 2003. Fisheries management. 2. The ecosystem approach to fisheries. FAO Technical Guidelines for Responsible Fisheries 4, Supplement 2. FAO, Rome, Italy.

Food and Agriculture Organization of the United Nations (FAO). 2009. Fisheries management. 2. The ecosystem approach to fisheries. 2.2. Human dimensions of the ecosystem approach to fisheries. FAO Technical Guidelines for Responsible Fisheries 4, Supplement 2, Addendum 2. FAO, Rome, Italy.

Gaventa, J. 2006. Finding the spaces for change: a power analysis. IDS Bulletin 37(6):23-33. http://dx.doi.org/10.1111/j.1759-5436.2006. tb00320.x

Gilmour, J. M. 1972. The spatial evolution of manufacturing: southern Ontario, 1851-1891. University of Toronto Press, Toronto, Ontario, Canada.
Isaacs, M. 2013. Small-scale fisheries governance and understanding the snoek (Thyrsites atun), supply chain in the Ocean View fishing community, Western Cape, South Africa. Ecology and Society 18(4): 17. http://dx.doi.org/10.5751/ ES-05863-180417

Jarre, A., S. M. Ragaller, and L. Hutchings. 2013. Long-term, ecosystem-scale changes in the southern Benguela marine pelagic social-ecological system: interaction of natural and human drivers. Ecology and Society 18(4): 55. http://dx.doi.org/10.5751/ ES-05917-180455

Jentoft, S., and R. Chuenpagdee. 2009. Fisheries and coastal governance as a wicked problem. Marine Policy 33:553-560. http://dx.doi.org/10.1016/j.marpol.2008.12.002

Khan, A. S., and B. Neis. 2010. The rebuilding imperative in fisheries: clumsy solutions for a wicked problem? Progress in Oceanography 87:347-356. http://dx.doi.org/10.1016/j.pocean.2010.09.012

Nayak, P. K. 2013. The Chilika Lagoon social-ecological system: an historical analysis. Ecology and Society 19(1): 1. http://dx.doi. org/10.5751/ES-05978-190101

Neis, B., S. Gerrard, and N. G. Power. 2013. Women and children first: the gendered and generational social-ecology of smallerscale fisheries in Newfoundland and Labrador and northern Norway. Ecology and Society 18(4): 64. http://dx.doi.org/10.5751/ ES-06010-180464

North, D. C. 1961. The economic growth of the United States, 1790-1860. Prentice-Hall, Englewood Cliffs, New Jersey, USA.

Norton, M. 2013. The life and times of snoek. Ecology and Society 18(4): 32. http://dx.doi.org/10.5751/ES-05866-180432

Ommer, R. E. 1988. What's wrong with Canadian fish? Pages 23-44 in Peter R. Sinclair, editor. A question of survival: the fisheries and Newfoundland society. ISER Books, St. John's, Newfoundland and Labrador, Canada.

Ommer, R. E. 1990. From outpost to outport. McGill University Press, Montreal, Quebec, Canada.

Ommer, R. E., R. I. Perry, G. Murray, and B. Neis. 2012. Socialecological dynamism, knowledge, and sustainable coastal marine fisheries. Current Opinion in Environmental Sustainability 4:316-322. http://dx.doi.org/10.1016/j.cosust.2012.05.010

Paterson, B., C. Kirchner, and R. E. Ommer. 2013. A short history of the Namibian hake fishery-a social-ecological analysis. Ecology and Society 18(4): 66. http://dx.doi.org/10.5751/ ES-05919-180466

Paterson, B., and S. L. Petersen. 2010. EAF implementation in Southern Africa: lessons learnt. Marine Policy 34:276-292. http:// dx.doi.org/10.1016/j.marpol.2009.07.004

Watkins, M. H. 1963. A staple theory of economic growth. Canadian Journal of Economics and Political Science 29 (2):141-158. http://dx.doi.org/10.2307/139461 